(c) 2018. This manuscript version is made available under the CC-BY-NC-ND 4.0 license http://creativecommons.org/licenses/by-nc-nd/4.0/

\title{
1 Auxiliary consumption: a necessary energy that affects thermoelectric
}

\section{generation}

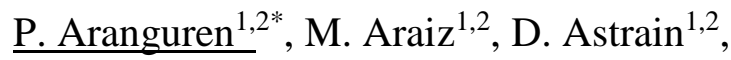 \\ ${ }^{1}$ Mechanical, Energy and Materials Engineering Department Public University of \\ Navarre, 31006 Pamplona, Spain \\ ${ }^{2}$ Smart Cities Institute, Pamplona, Spain \\ *e-mail:patricia.arangureng@unavarra.es
}

Keywords: water cooling; auxiliary consumption; thermoelectric generation; optimization; waste heat harvesting

\section{Abstract}

Waste heat recovery can apply to a wide range of applications, from transportation, or industries to domestic applications. The attempts to increase the efficiency of thermoelectric generators to make this technology appealing for waste heat harvesting include the study of novel heat exchangers to be located at the generators. A liquid cooling fluid presents high heat transfer coefficients. However, it needs a pump to make it circulate through the system. Besides, to have a constant input of fresh refrigerant, the dissipation systems need secondary heat exchangers to cool down the refrigerant, so as it can be reused again. A computational methodology, which simulates the behavior of thermoelectric generators has been used to determine the potential of waste heat harvesting. The optimal thermoelectric energy obtained using heat dissipation systems with liquid as the heat-carrier is $119 \mathrm{MWh} /$ year, while the maximum net energy, the usable energy, is $73 \mathrm{MWh} / \mathrm{year}$ due to the consumption of the auxiliary equipment. The latest value does represent not only a $40 \%$ reduction from the optimal thermoelectric 
25 generation but also a different optimal working point. The complete elimination of the

26 auxiliary equipment at this application could produce up to $128 \mathrm{MWh} /$ year.

\section{Nomenclature}

$\delta \quad$ Occupancy ratio

$\rho_{l} \quad$ Density of the water $\quad \mathrm{Kg} / \mathrm{m}^{3}$

$\Delta p_{C P} \quad$ Hydraulic losses of the cold plate $\quad \mathrm{kPa}$

$\Delta p_{f} \quad$ Hydraulic losses of the fan-coil $\quad \mathrm{kPa}$

$\Delta p_{23} \quad$ Hydraulic losses of the refrigeration system between the exit of $\mathrm{kPa}$ the cold plate and the entry of the fan-coil

$\Delta p_{41} \quad$ Hydraulic losses of the refrigeration system between the exit of $\mathrm{kPa}$ the fan-coil and the entry of the cold plate

$\eta_{\text {pump }} \quad$ Efficiency of the pump

$A_{T E M} \quad$ Area of a TEM $\mathrm{m}^{2}$

$A_{\text {dis }} \quad$ Available dissipative area $\quad \mathrm{m}^{2}$

$M_{T E M} \quad$ Number of TEMs

$\dot{m}_{a} \quad$ Mass flow of the air $\quad \mathrm{kg} / \mathrm{s}$

$\dot{m}_{\text {gas }} \quad$ Mass flow of the flue gases $\mathrm{kg} / \mathrm{s}$

$\dot{m}_{l} \quad$ Mass flow of the refrigerant liquid $\mathrm{kg} / \mathrm{s}$

$\dot{Q}_{C} \quad$ Calorific power to dissipate $\quad$ W

$\dot{Q}_{C P} \quad$ Calorific power dissipated by the cold plate W

$\dot{Q}_{f} \quad$ Calorific power dissipated by the fan-coil $\quad$ W

$\dot{Q}_{23} \quad$ Calorific power dissipated by the refrigeration system between W the exit of the cold plate and the entry of the fan-coil 
$\dot{Q}_{41} \quad$ Calorific power dissipated by the refrigeration system between $\mathrm{W}$ the exit of the fan-coil and the entry of the cold plate

$R_{C}^{T E M} \quad$ Thermal resistance of the heat exchanger located on the cold $\mathrm{K} / \mathrm{W}$ side per thermoelectric module

$R_{C} \quad$ Thermal resistance of the heat exchanger located on the cold $\mathrm{K} / \mathrm{W}$ side

$\begin{array}{lll}R_{C P} & \text { Thermal resistance of the cold plate } & \mathrm{K} / \mathrm{W}\end{array}$

$\begin{array}{lll}T_{1} & \text { Temperature at the entry of the cold plate }\end{array}$

$T_{2} \quad$ Temperature at the exit of the cold plate $\quad \mathrm{K}$

$T_{3} \quad$ Temperature at the entry of the fan-coil $\mathrm{K}$

$T_{4} \quad$ Temperature at the exit of the fan-coil $\quad \mathrm{K}$

$\begin{array}{lll}T_{a m b} & \text { Ambient temperature } & \mathrm{K}\end{array}$

$\begin{array}{ll}T_{C P} & \text { Temperature of the cold plate }\end{array}$

$U \quad$ Overall heat transfer coefficient $\quad \mathrm{W} / \mathrm{m}^{2} \mathrm{~K}$

$\dot{W}_{\text {aux }} \quad$ Consumption of the auxiliary equipment $\quad$ W

$\dot{W}_{\text {fan }} \quad$ Electrical consumption of the fans $\quad$ W

$\dot{W}_{\text {pump }} \quad$ Electrical consumption of the pump $\quad$ W

$\dot{W}_{T E M} \quad$ Thermoelectric generation $\quad$ W

$\dot{W}_{\text {net }}$ Net generation $\quad$ W

\section{Introduction}

31 Despite the gratuity of waste heat, the low efficiency that thermoelectric generation

32 presents is a deterrent for the applicability and profitability of big scale systems. Thus,

33 great efforts to improve the efficiency of thermoelectric generators (TEGs) are being

34 made. The two most important actions are the improvement of the thermoelectric 
materials and the thermal optimization of the TEG as a whole. To fulfill the latter aspect new different types of heat exchangers are nowadays studied aiming to reduce the thermal resistances on both sides of the thermoelectric modules (TEMs), as they would procure higher thermoelectric generation [1,2]. One of the approaches is to include liquid refrigerants into the heat dissipation systems to improve the thermal resistances [3-5]. Due to their heat transfer coefficients their thermal resistances are good, however extra power consumption is needed since a pump is required to make the refrigerant circulate along the circuit. Thus, to optimize the net generation (the thermoelectric generation minus the consumption of the auxiliary equipment), the increase on thermoelectric generation and the increment of the auxiliary consumption have to be born in mind $[6,7]$. The effect of longitudinal vortex generators and the introduction of inserts or metal foams enhance heat transfer, but they provoke higher pressure drops, and hence the consumption of the pumps greatly increases $[6,8-10]$. The increase in thermoelectric generation could not be as noticeable as the growth in the auxiliary consumption, obtaining lower net generations $[6,11,12]$, a totally non-desirable scenario.

Moreover, most of the studies of the literature do not take into account the necessity of reducing the temperature of the refrigerant. Due to the heat absorbed by the fluids when they circulate through the heat exchangers, their temperature increases. Therefore, the temperature of the refrigerants needs be lowered for continuous operation. The dissipator in charge of decreasing the temperature of the fluid increases the thermal resistance of the refrigeration system, worsening the thermoelectric generation. Besides, this exchanger could include auxiliary equipment, hence extra consumption needs to be redrawn from the thermoelectric generation $[13,14]$. To complete eliminate the auxiliary equipment, novel heat exchangers are used where the fluid circulates thanks to phase change and sometimes gravity. These devices improve 
even more the heat transfer due to the use of the latent heat of the internal fluid [15]. The

61 fluid evaporates due to the heat absorbed at the evaporator. It flows up to the condenser, where it releases heat to the ambient and condensates. Finally, the liquid returns to the evaporator closing the loop. Thermosyphons could eliminate the necessity of including any auxiliary equipment if they present free convection with the ambient, however as they lack of wick, they need to work vertically so gravity brings back the condensed fluid to the evaporator [16]. Many novel applications are including these devices into TEGs, variable conductance heat pipe/thermosiphon allow the TEG to work at constant hot face temperature during a driving cycle [17], waste heat recovery using heat pipes and TEG to produce electricity [18] or power generation from solar ponds using combined thermosiphon and TEGs [19].

The optimization of the thermal design of TEGs is essential to improve their efficiency. Not only the heat exchangers and their mass flows have to be optimized, but also the number of TEMs used. The occupancy ratio (equation (1)), determines the thermoelectric generation. A higher number of TEMs seems to produce higher thermoelectric generation, but as the thermal resistance per TEM of each heat exchanger worsens, it is not always true that a bigger $\delta$ produces higher thermoelectric generation [20-22].

$$
\delta=\frac{M_{T E M} A_{T E M}}{A_{\text {dis }}}
$$

This paper studies two dissipators: a heat dissipation system with water as the heat-carrier and a thermosyphon that refrigerate a TEG located at the exhaust of a real furnace. To that purpose, a general methodology makes two validated computational models $[13,23]$ interact to optimize the net thermoelectric generation modifying the occupancy ratio, the

81 mass flow of the refrigerants and the consumption of the auxiliary equipment. The

82 influence on the net generation of including the secondary heat exchanger in charge of 83 reducing the temperature of the water and the auxiliary consumption is quantified, 
84 highlighting the fact that those influences are not negligible and should be taken into 85 account for the design of TEG systems.

\section{Thermoelectric generation optimization methodology}

87 TEG systems produce electric energy out of temperature gradients. TEGs can be applied to any application where a difference of temperature exists, however, applications, where waste heat exists, are very promising, as waste heat is costless and it appears at any application. To optimize the net thermoelectric generation (equation (2)) two validated computational models interact and seek the optimal working point. One computational model simulates the thermal resistance of the dissipation system with liquid as the heatcarrier (Refrigeration System computational model (RS model)) and obtains the

94 consumption of the auxiliary equipment (equation (3)) [13]. The second one simulates the thermoelectric generation of any application (Thermoelectric Generator computational model (TEG model)), but especially those which present waste heat conducted through a pipe to the ambient [23]. The whole methodology includes the occupancy ratio, the mass flow of the refrigerants, the calorific power to dissipate and the

99 temperature variation of the heat source.

$$
\begin{gathered}
\dot{W}_{n e t}=\dot{W}_{T E M}-\dot{W}_{a u x} \\
\dot{W}_{a u x}=\dot{W}_{\text {pump }}+\dot{W}_{\text {fan }}
\end{gathered}
$$

100 Figure 1 presents the methodology to compute the net thermoelectric generation of any 101 application, especially those applications where electric energy is obtained from waste 102 heat emitted as flue gases to the atmosphere. The presented interaction includes heat

103 exchangers with liquid as the heat-carrier on the cold side of the generators, but the same

104 methodology could be used to obtain the generation of any system involving any other 105 kind of heat dissipators. 
106 The RS model obtains the thermal resistance of the heat exchanger as a function of the

107 calorific power to dissipate, an output of the thermoelectric generation model. To solve

108 this aspect, firstly the calorific power is estimated to obtain the thermal resistance, a

109 necessary input for the TEG model. The latter computational model solves the

110 thermoelectric phenomena and obtains the calorific power dissipated by the cold side heat

111 exchanger, the new value that closes the iteration loop. Once the solution is reached, the

112 thermoelectric generation is obtained and given the consumption of the auxiliary

113 equipment; the net generation is computed, the parameter to optimize.

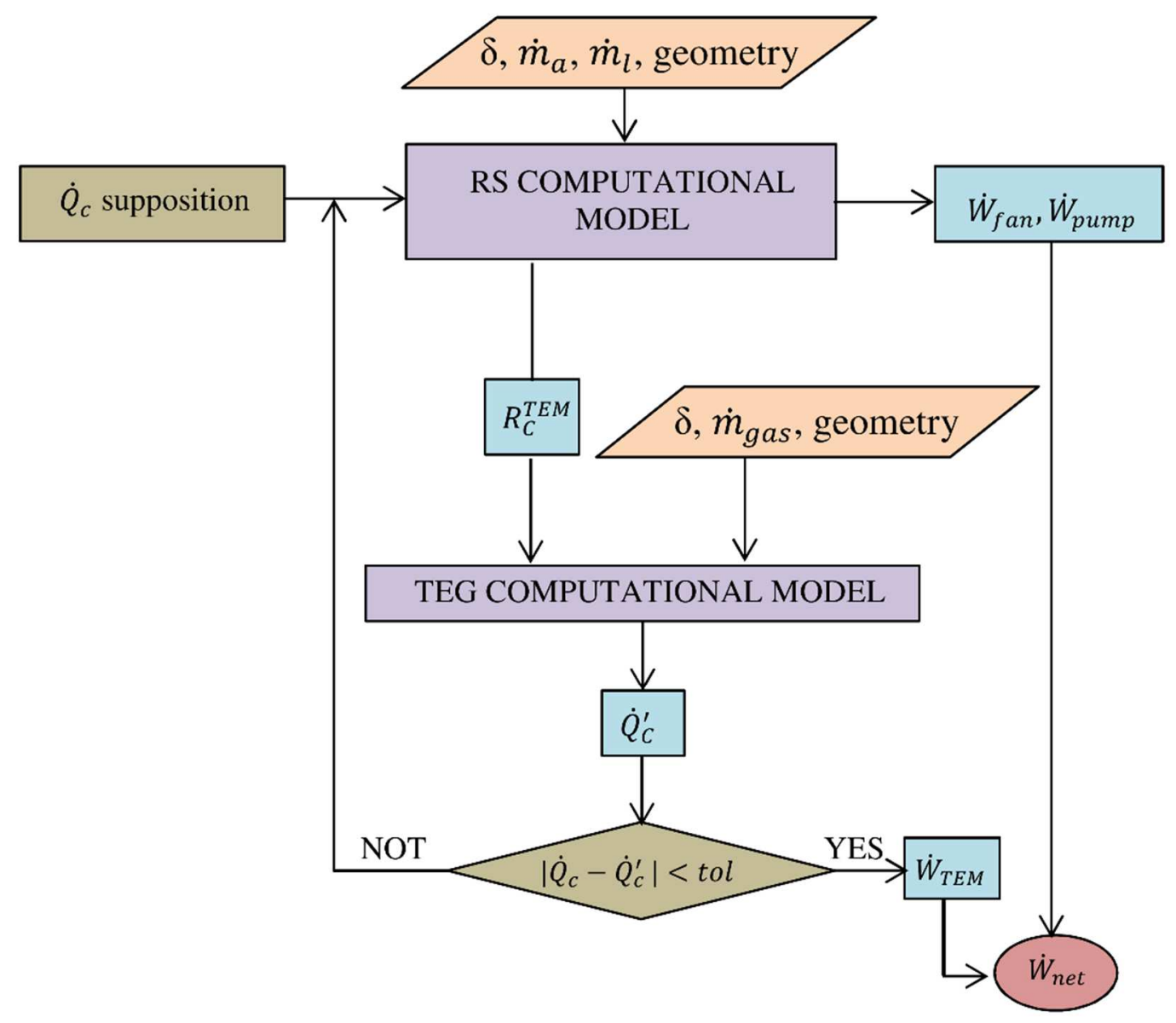

115 Figure 1. Interaction between the refrigeration system and the thermoelectric generation computational model 
118 This model is specially developed for applications where TEGs harvest heat from flue

119 gases which flow along a pipe. This model includes the temperature drop of the flue gases

120 while they exchange heat with the TEG system, a significant variable variation as the

121 thermoelectric generation of a built prototype was reduced by a $65 \%$ due to the

122 temperature drop of the gases between two different levels. The error of this

123 computational model is the $\pm 12 \%$ [23].

124 The TEG computational model uses the finite differences method to solve the 125 thermoelectric phenomena. Moreover, this model includes each component of the system:

126 the contacts, the ceramics of the TEMs, each thermoelectric effect, novel parameters such

127 as the mass flow of the refrigerants, the occupancy ratio and the temperature decrease of 128 the flue gases, as well as it takes into account the temperature dependence of the

129 thermoelectric properties, and it solves the transient state.

130 The TEG computational model needs the thermal resistances of the different elements of

131 the generator to calculate the thermoelectric generation. Including heat exchangers with

132 fluid as the heat-carrier into a TEG improves the thermoelectric generation, but the net

133 generation has to be computed, as it is not that trivial to assure that in any case, the

134 incorporation of this kind of heat dissipators is right for this generation. Hence a 135 refrigeration system computational model is developed and included in the calculation 136 methodology.

\section{b. Refrigeration system computational model}

138 The use of a heat exchanger with liquid as a heat-carrier to dissipate the heat emitted by

139 a TEG involves the inclusion of extra elements, such as a pump to drive the fluid and a

140 secondary heat exchanger to cool down the refrigerant to be reused again. Figure 2

141 presents a conventional heat dissipation system located on the cold side of a TEM. The

142 heat to be dissipated $\left(\dot{Q}_{C}\right)$ is absorbed by the refrigerant fluid which is driven through the 
143 whole circuit by the pump. The secondary heat exchanger cools down the temperature of

144 the refrigerant. This heat dissipator normally transfers heat to the surrounding air and it

145 is commonly provided with a fan to improve the convection with the ambient.

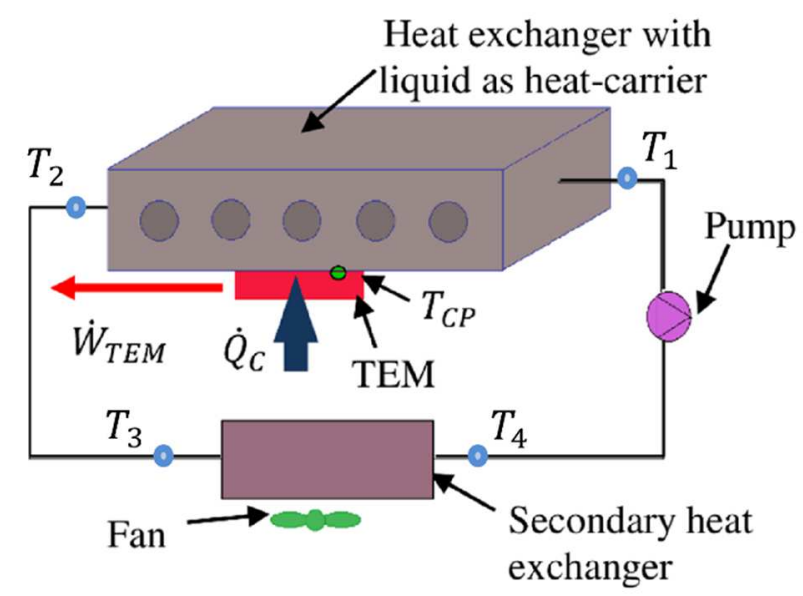

147 Figure 2. Heat dissipation system including a heat exchanger with liquid as the heatcarrier [14]

149 A computational methodology, which includes influential parameters such as the occupancy ratio $(\delta)$, the mass flow of the refrigerants $\left(\dot{m}_{a}, \dot{m}_{l}\right)$ and the calorific power to

151 dissipate $\left(\dot{Q}_{C}\right)$ was developed to characterize the thermal resistance per TEM of the whole 152 refrigeration system [13]. This model presents an accuracy of the $93 \%$ and its schematic 153 can be consulted in Figure 3.

154 A range of mass flows are simulated in order to obtain the working point of the 155 refrigeration system, The upper limit of the mass flow is denoted as $\mathrm{M}$ and can be selected 156 by the user. Within each mass flow, the computational model calculates the heat transfer 157 coefficients (U) of the different elements of the system through an iteration loop using 158 the entry and exit temperatures of the cold plate and fan-coil $\left(T_{1}, T_{2}, T_{3}\right.$ and $\left.T_{4}\right)$ and the 159 pressure drops are obtained to calculate the working point of the system, obtaining the 160 thermal resistance of the system and the consumption of the auxiliary equipment. 
161 The thermal resistance per TEM of the whole refrigeration system is defined by equation

162 (4). The temperature difference between the cold plate and the ambient is divided by the

163 calorific power dissipated and the number of TEMs. This thermal resistance includes the

164 thermal resistance of the heat exchanger located on the cold side of the TEMs, known as

165 a cold plate, the resistance of the secondary heat exchanger and that of the pipes and the

166 rest of the devices involved in the refrigeration system. The auxiliary consumption of the

167 fan of the secondary heat exchanger as well as the consumption of the pump are included

168 into the total auxiliary consumption (equation (2)), the electrical power to be redrawn

169 from the thermoelectric generation to obtain the usable electrical generation $\left(\dot{W}_{\text {net }}\right)$

170 expressed in equation (1).

$$
R_{C}^{T E M}=\frac{T_{C P}-T_{a m b}}{\dot{Q}_{C} / M_{T E M}}
$$

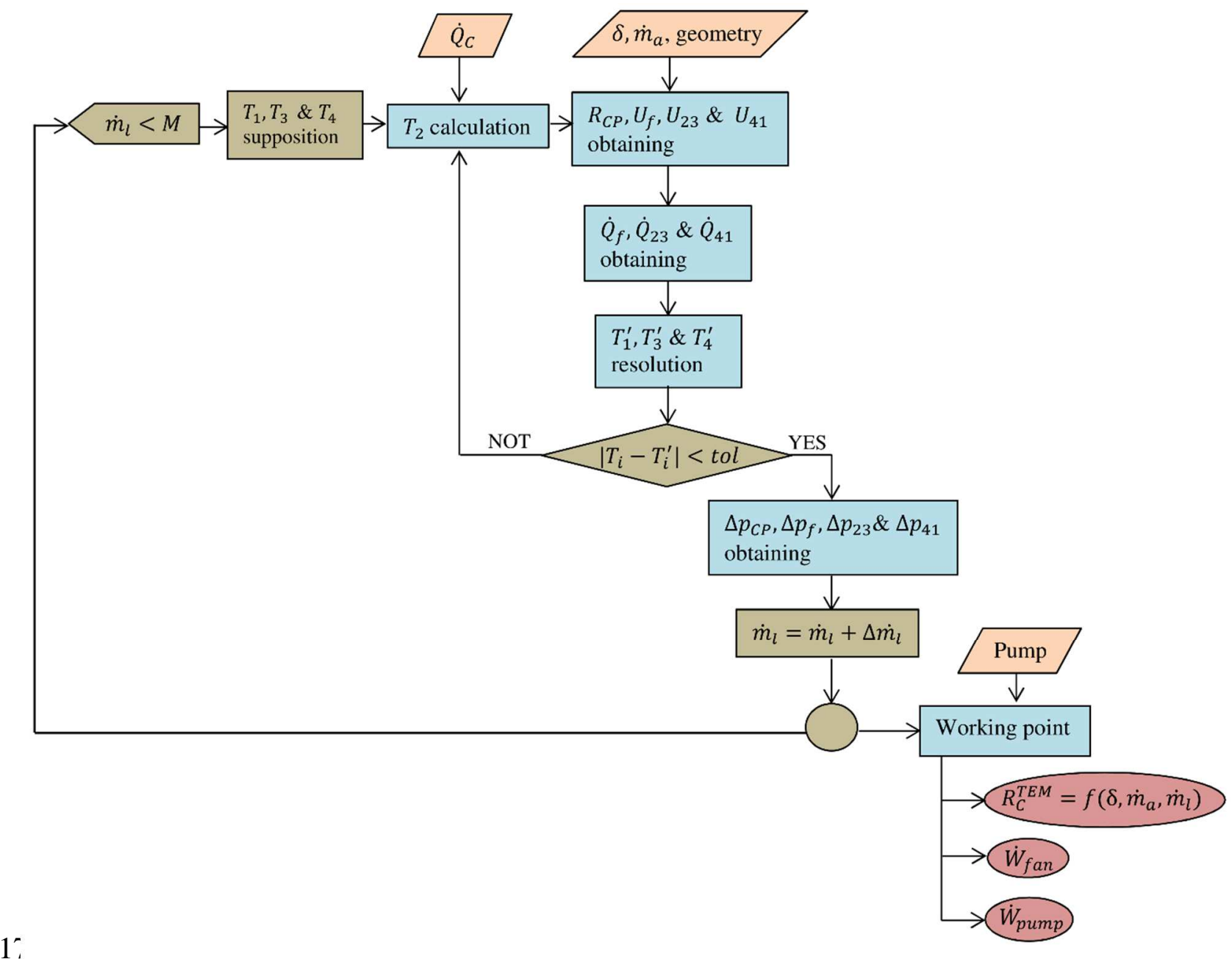


Figure 3. Schematic of the computational model that obtains the thermal resistance of the heat dissipation system [13]

\section{Optimization study}

176 To estimate the potential of the optimization methodology a real Spanish industry has

177 been selected. The consumption of thermal energy of this industry is massive, as it

178 includes ceramic cooking processes. Its waste heat, as high-temperature smoke emitted 179 to the ambient through the chimney, can be easily harvested through TEGs. The chimney

180 has a height of $12 \mathrm{~m}$ and a diameter of $0.8 \mathrm{~m}$, a total of $33.6 \mathrm{~m}^{2}$ to locate the thermoelectric

181 generator, while the flue gases have a mass flow of $\dot{m}_{g a s}=5.49 \mathrm{~kg} / \mathrm{s}$ and a temperature

182 of $187^{\circ} \mathrm{C}$. The ambient temperature is selected as $T_{a m b}=17^{\circ} \mathrm{C}$, the mean temperature of

183 the area where the industry is.

184 Every element has to be defined through its thermal resistance and heat capacity as Figure

1852 depicts. The thermoelectric modules simulated are TG12-8-01-L from Marlow

186 Industries, which support up to $250{ }^{\circ} \mathrm{C}$ on one of their sides due to special welding [24].

187 Their properties define their particularities. The hot side heat exchanger is selected to be

188 a finned dissipator with a fin spacing of $10 \mathrm{~mm}$, a fin high of $50 \mathrm{~mm}$ and a fin thickness

189 of $1.5 \mathrm{~mm}$. The base thickness is $4 \mathrm{~mm}$, and the finned dissipator is located in the interior

190 of the chimney. To get the thermal resistance of the heat dissipator a CFD software was used, ANSYS Fluent. The influence of the occupancy ratio, as well as the velocity of the

192 flue gases, have been evaluated, as Figure 4 depicts. The tendencies are similar, a higher

193 number of TEMs (higher occupancy ratios) present higher thermal resistances, due to the

194 reduction of the effective dissipative area per TEM, and higher velocities (higher mass

195 flow rates) procure smaller thermal resistances since the heat transfer coefficients 196 improve. 


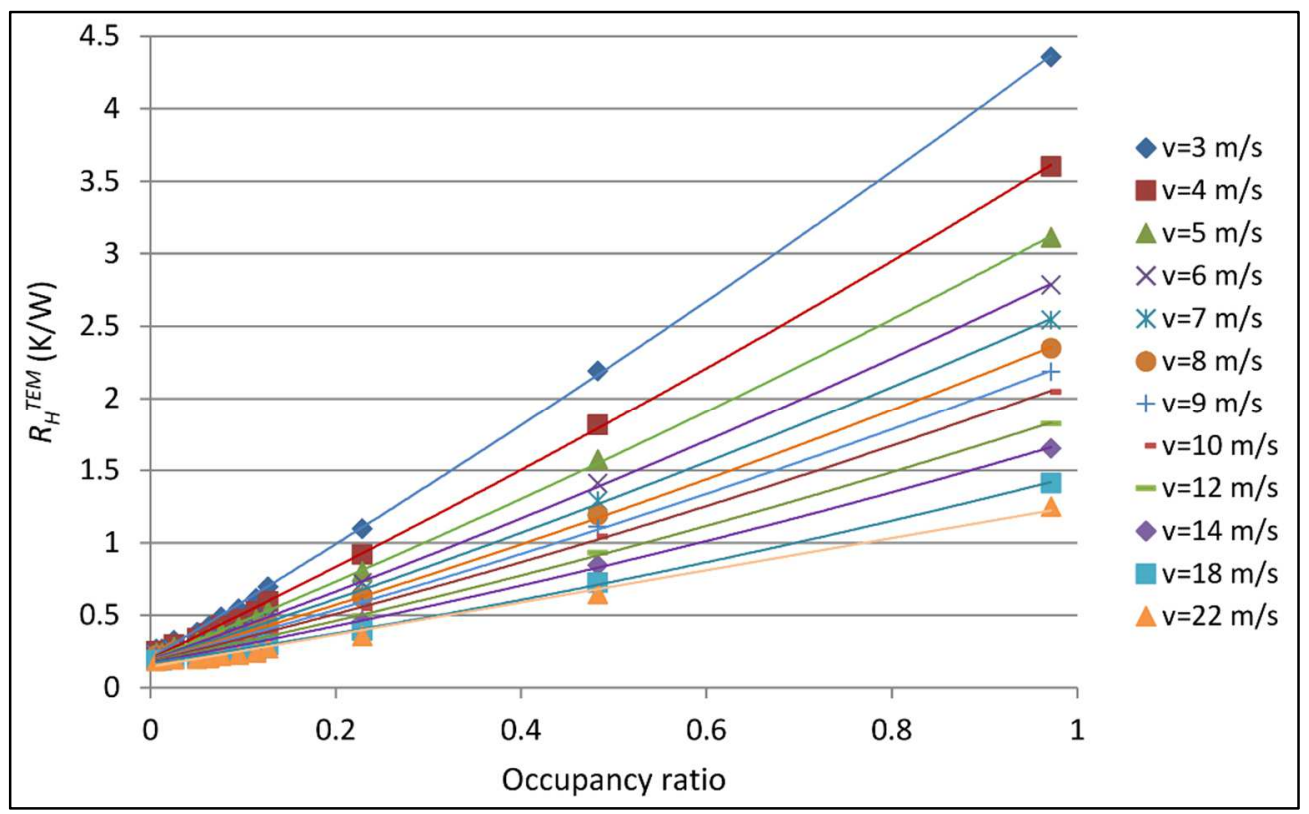

198 Figure 4. Thermal resistance per thermoelectric module of the finned dissipator located 199 on the hot side of the TEG as a function of the occupancy ratio and the velocity of the flue gases

a. Cold side heat exchanger thermal characterization

202 The RS computational model is used to characterize the cold side heat exchanger 203 thermally. The dissipation system is mainly composed of a cold plate formed by $6.2 \mathrm{~mm}$ 204 parallel channels separated $3 \mathrm{~mm}$, a fan-coil provided with $8 \mathrm{~mm}$ copper tubes, 205 longitudinal fins with a thickness of $0.2 \mathrm{~mm}$ and separated $1.6 \mathrm{~mm}$ provided with fans 206 that make the air circulate through its fins and a pump that makes the water circulate along 207 the circuit. The cold plate is located on the hot side of the TEMs while the fan-coil is 208 located at the bottom of the chimney, where the water is cooled down to be reused again.

209 The thermal characterization has been done modifying four parameters: the calorific 210 power to dissipate $\left(100<\dot{Q}_{C}<500 \mathrm{~W}\right)$, the occupancy ratio $(0.073<\delta<0.625)$, the water 211 mass flow $\left(0.024<\dot{m}_{l}<0.055 \mathrm{~kg} / \mathrm{s}\right)$ and the air mass flow along the fan-coil $212\left(0.090<\dot{m}_{a}<0.243 \mathrm{~kg} / \mathrm{s}\right)$. 
213 Figure 5 presents the influence of the calorific power to dissipate on the thermal resistance

214 by TEM of the dissipation system for different air mass flows. As the figure depicts, the

215 range of calorific powers simulated slightly influences the thermal resistance as the

216 calorific power to dissipate influences the temperature of the water that circulates through

217 the system. Due to its high specific heat, the maximum difference in temperature is $4{ }^{\circ} \mathrm{C}$,

218 a very small temperature difference to cause significant changes in the heat transfer

219 coefficients, and thus on the thermal resistance of the system. Even though there is a

220 decreasing tendency, the slope is so small as to neglect the influence of the calorific power

221 to dissipate on the thermal resistance per TEM of the system.

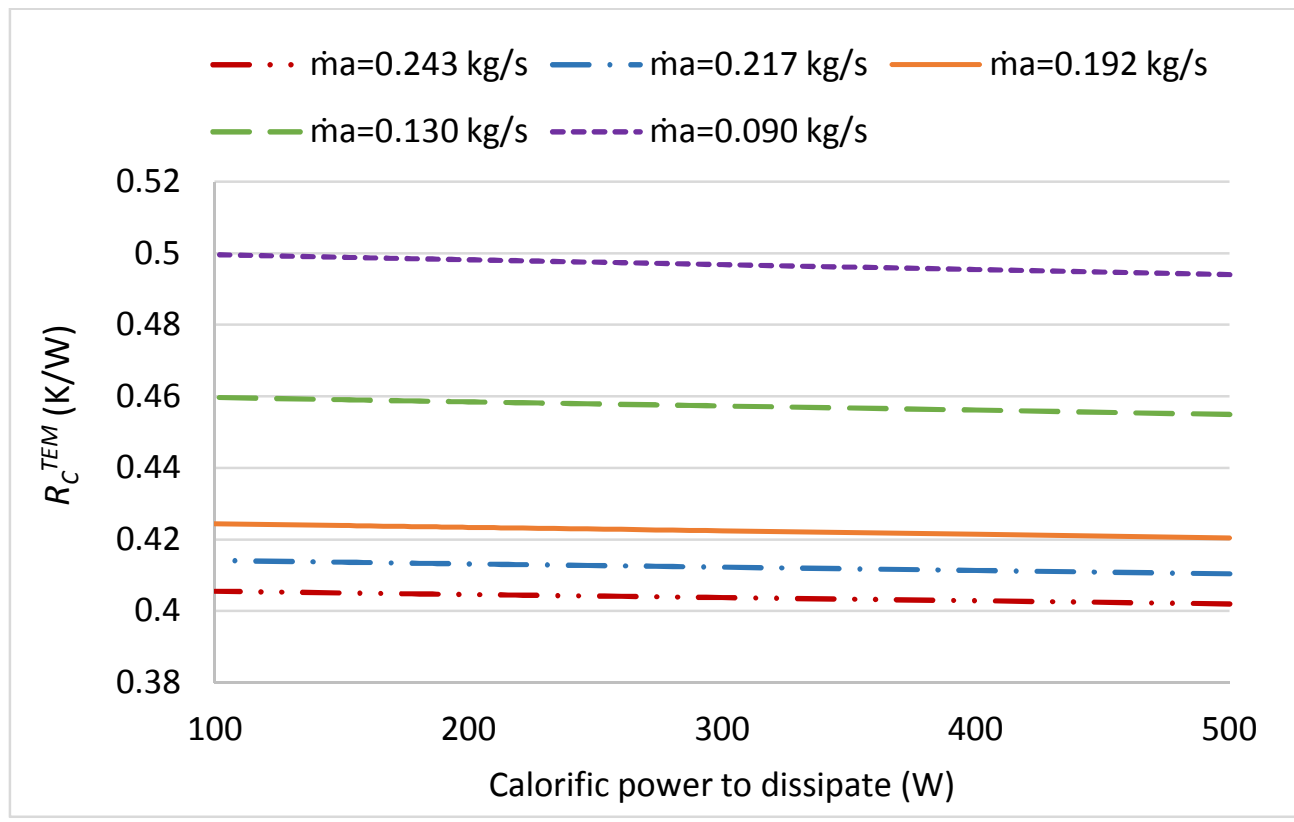

223 Figure 5. Thermal resistance per TEM of the dissipation system with liquid as the heatcarrier as a function of the calorific power to dissipate and the air mass flow for a

226 Figure 6 and Figure 7 present the influence of the occupancy ratio (the number of TEMs

227 installed) and the mass flow of the refrigerants on the thermal resistance of the 228 refrigeration system. As the occupancy ratio increases, adding more TEMs, the thermal 229 resistance per TEM increases. The increment of the number of TEMs means a reduction 
230 in the effective dissipative area devoted to each TEM, and thus an increase in the thermal

231 resistance. Therefore, an increase of $\delta$ does not always mean an increment on the

232 thermoelectric generation, as it will be analyzed later on.

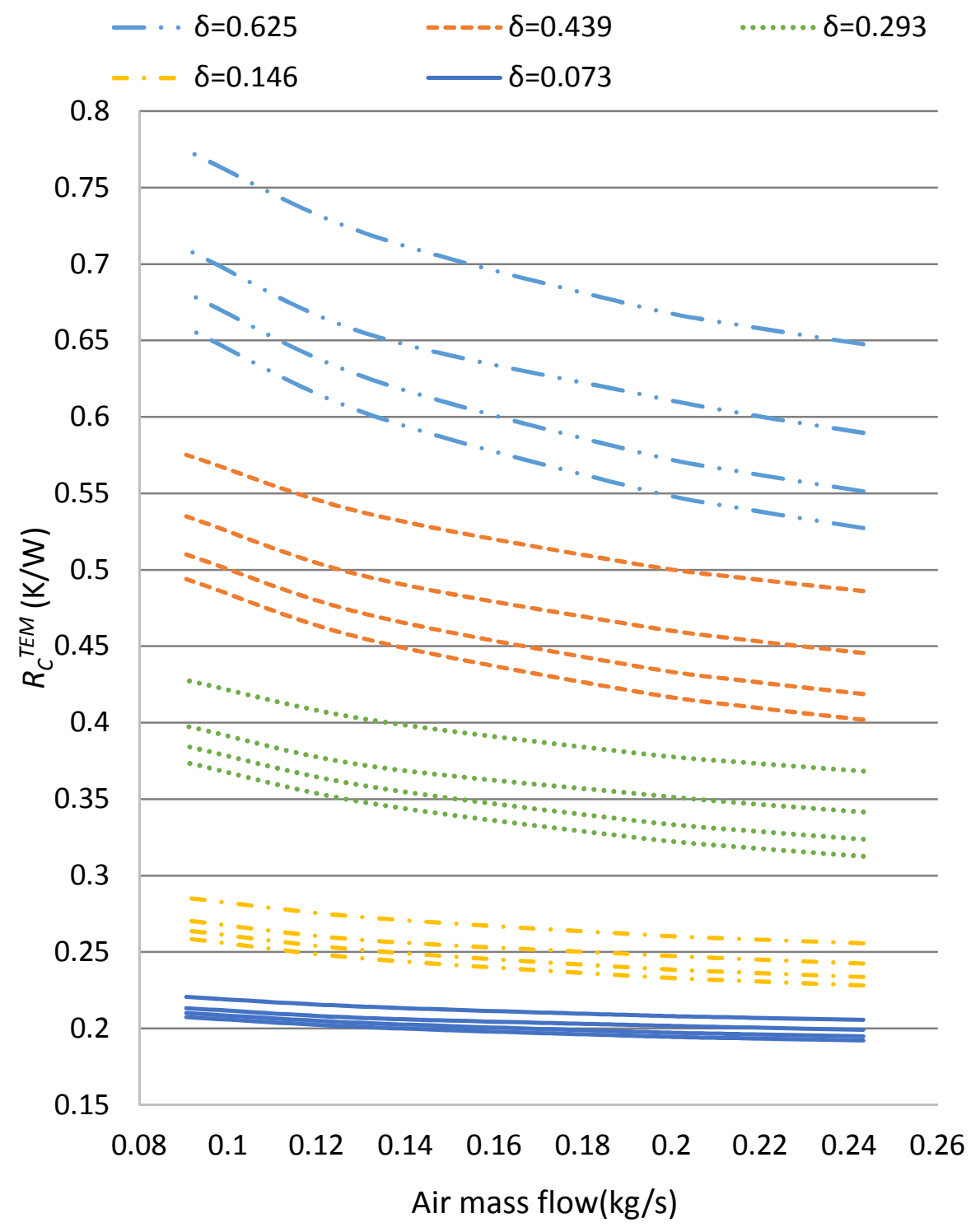

Figure 6. Thermal resistance per TEM of the dissipation system with liquid as the heatcarrier as a function of the occupancy ratio and the air and water mass flows. $\dot{m}_{l}=0.024$; $0.035 ; 0.044$ and $0.055 \mathrm{~kg} / \mathrm{s}$.

238 The four different curves of each occupancy ratio that can be seen in Figure 8 correspond to the four different water mass flows simulated $\left(\dot{m}_{l}=0.024 ; 0.035 ; 0.044\right.$ and $\left.0.055 \mathrm{~kg} / \mathrm{s}\right)$, 
240 the biggest water mass flow is represented by the bottom curve while the smallest by the

241 upper one of each $\delta$. The mass flow of the air highly influences the thermal resistance of

242 the system for high occupancy ratios, whereas when small occupancy ratios the influence

243 is less significant. High occupancy ratios procure small effective dissipative areas per

244 TEM. Hence, an improvement of the heat transfer coefficients, through the increment of

245 the refrigerant mass flows, greatly influences the thermal resistance. Figure 9 presents the

246 same tendency for the water mass flow for different occupancy ratios. The surfaces of the

247 smallest $\delta$ are practically horizontal, while the biggest occupancy ratios surfaces present

248 a wider range of thermal resistances.

249

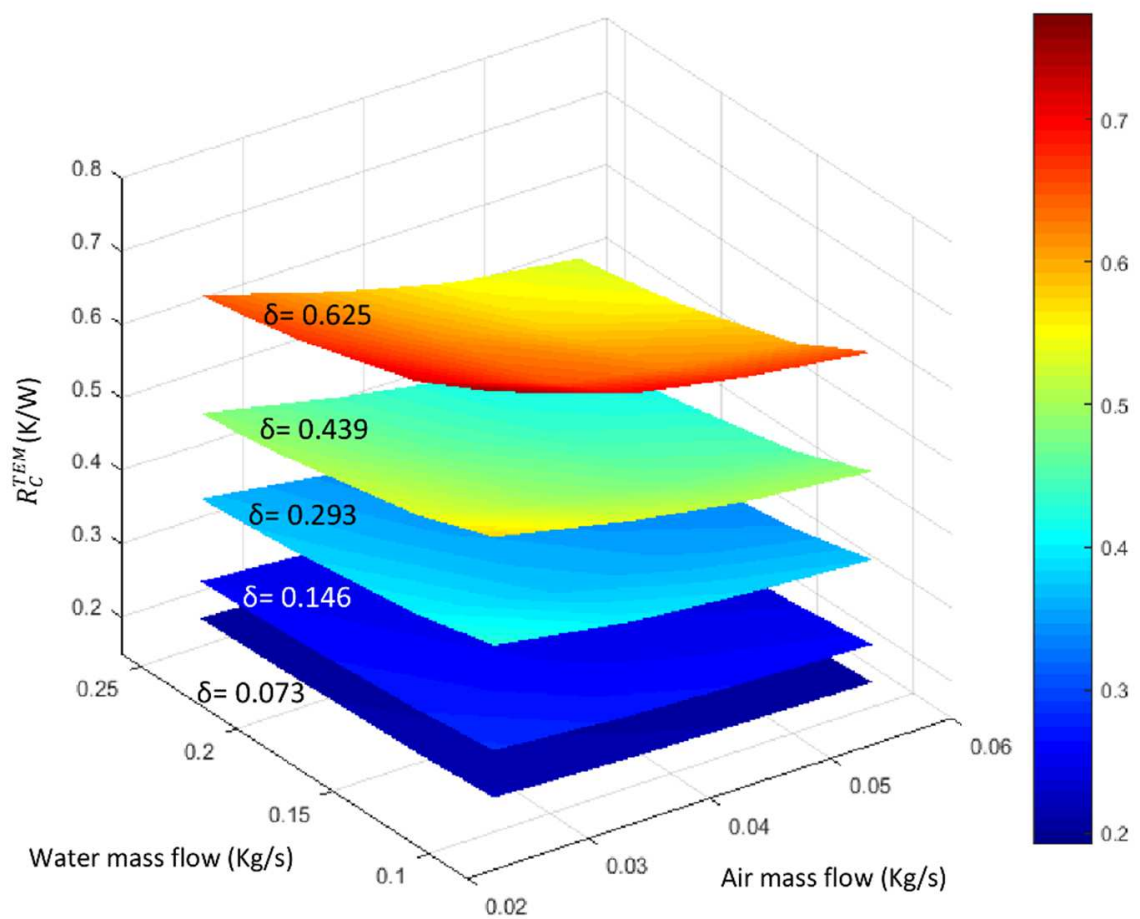

251 Figure 7.3D plot of the influence of the occupancy ratio and the refrigerant mass flows on the thermal resistance of the refrigeration system per TEM

253 The occupancy ratio $(\delta)$ and the refrigerant mass flows $\left(\dot{m}_{a}, \dot{m}_{l}\right)$ are factors that determine

254 the thermal resistance per TEM of the refrigeration system with water as the heat-carrier

255 as Figure 6 and Figure 7 present. However, the calorific power to dissipate $\left(\dot{Q}_{C}\right)$ is not 
256 influential as Figure 7 depicts. The thermal resistances of the heat exchangers are decisive

257 for the thermoelectric generation, thus these parameters are going to be introduced into

258 the general computational methodology to maximize the net thermoelectric generation.

\section{b. Net thermoelectric generation}

260 Figure 8 shows the thermoelectric generation as a function of the occupancy ratio and the

261 mass flows of the refrigerants, the water that circulates through the system and the air that

262 helps to refrigerate the water at the fan-coil. This figure presents the importance of

263 selecting the optimal occupancy ratio as the maximum thermoelectric generation occurs

264 when $\delta=0.439$ (when the $43.9 \%$ of the surface of the chimney is covered by TEMs),

265 producing $14156 \mathrm{~W}$. The thermal resistance of the heat dissipation systems worsens if the

266 occupancy ratio increases, thus even a higher number of TEMs seems to provide higher

267 generation, as each module is producing less power the total generation could decrease,

268 as it happens for occupancy ratios greater than 0.439 . The thermoelectric generation rises

269 with the increase of both mass flows of the refrigerants. Higher mass flows procure better

270 thermal resistance, thus the difference in temperature between the hot and the cold sides

271 of the TEMs increase, producing more electric power. 


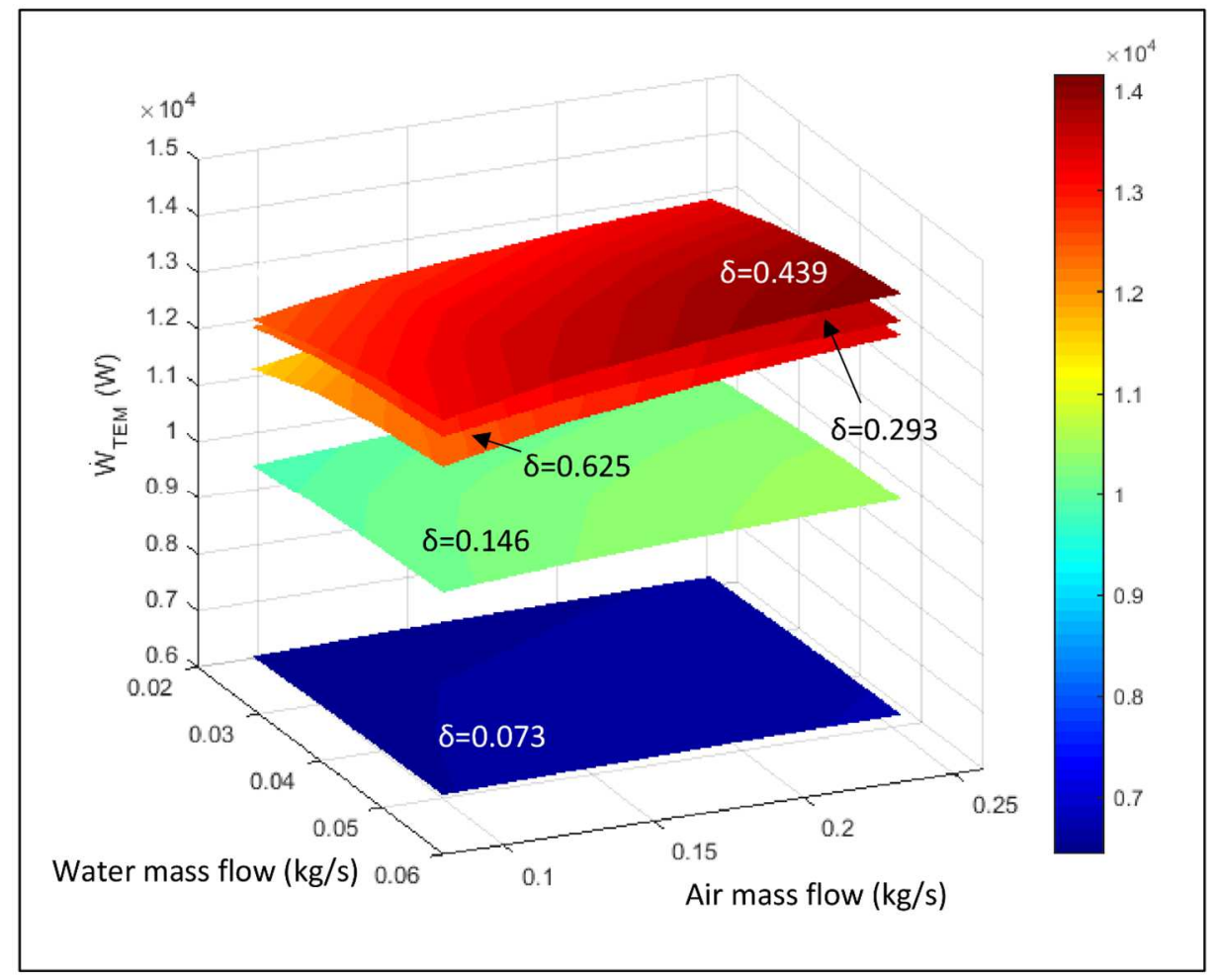

Figure 8. Thermoelectric generation as a function of the mass flow of the refrigerants and the occupancy ratios

275 Nevertheless, the increasing tendency of the thermoelectric generation with the increasing 276 of the mass flow of the refrigerants is not represented in Figure 9. The latter figure 277 presents the net generation, the thermoelectric generation minus the consumption of the auxiliary equipment, as a function of the mass flows of the refrigerants and the occupancy ratio. The maximum net generation equals $8703 \mathrm{~W}$, and it is found around an occupancy ratio of 0.4 . The increase in the mass flow of the refrigerants does not provide the same

281 tendency as with the thermoelectric generation. The net generation decreases if the mass

282 flows increase. This reduction is obtained by the increase of the consumption of the auxiliary equipment, which negatively influences the net generation. The increase of the thermoelectric generation due to the increments on the mass flows is less pronounced that the increase of the consumption of the auxiliary equipment. Some of the scenarios present in Figure 11 are not desirable because the net generation is negative, meaning that the auxiliary consumption is higher than the thermoelectric generation. 
288 The consumption of the auxiliary equipment has been calculated as the sum of the

289 consumption of the pump and that of the fans located at the fan-coil. The consumption of

290 the pump is obtained using equation (5) [25], where $\Delta P_{C P}$ stands for the pressure drop at

291 the cold plate and the efficiency of the pump ( $\left.\eta_{\text {pump }}\right)$ was selected to be the $80 \%$. To

292 account for the consumption of the fans at the fan-coil, the total electric consumption of

293 the fan-coil of the prototype defined by the air mass flow has been multiplied by 769 , as

294769 cold plates like the prototype one could fit on the surface of the chimney.

$$
\dot{W}_{\text {pump }}=\frac{\Delta P_{C P} \dot{m}_{l} / \rho_{l}}{\eta_{\text {pump }}}
$$

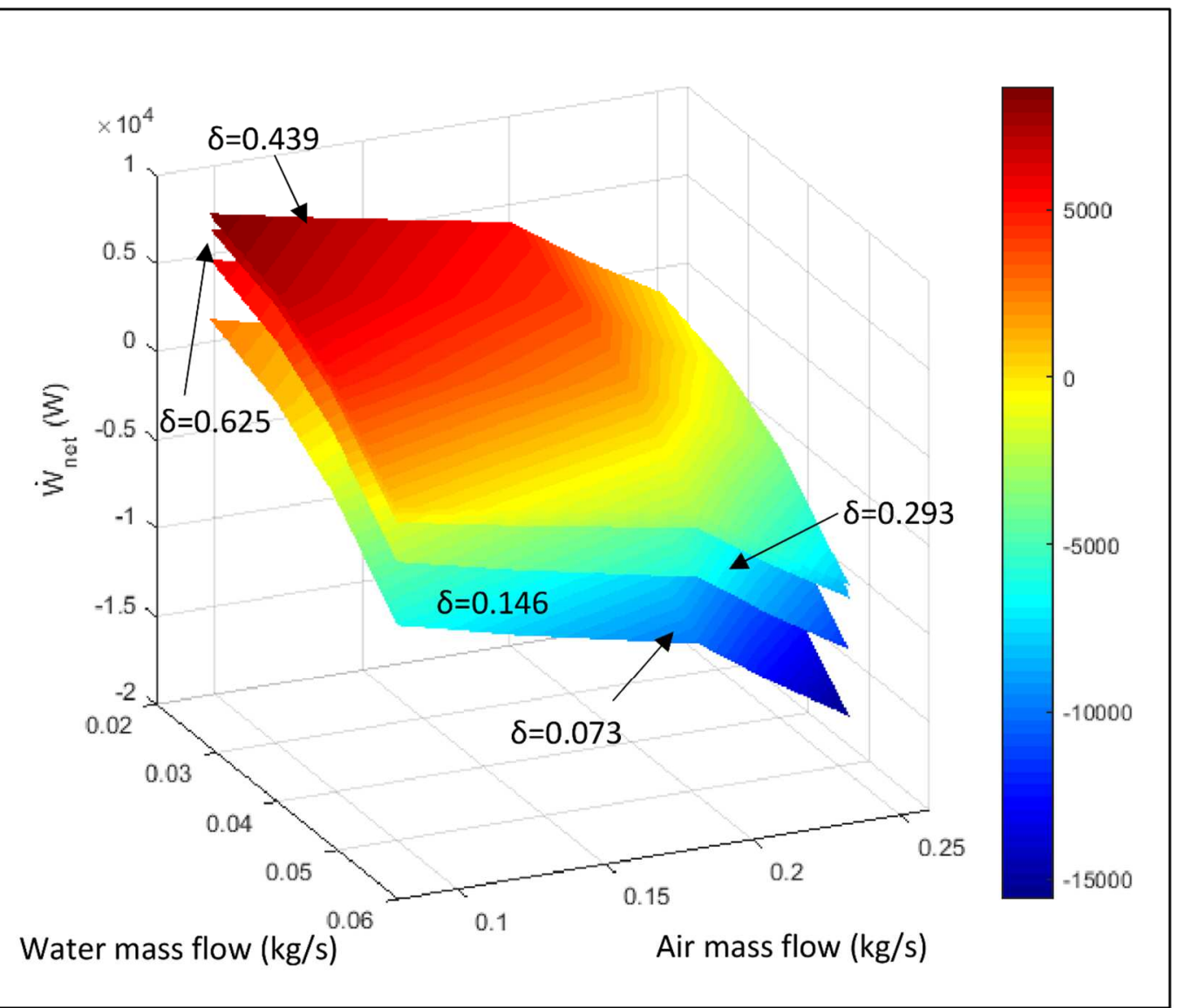

Figure 9. Net generation as a function of the mass flow of the refrigerants and the occupancy ratios

298 The influence of accounting for all the consumption of the auxiliary equipment is notorious. The maximum thermoelectric generation is $14156 \mathrm{~W}$ (119 MWh/year given 
300 that the furnace works 350 days a year), while the maximum net generation is reduced by

301 a $40 \%$, resulting in $8703 \mathrm{~W}$ (73 MWh/year). Besides, the optimum scenario is not 302 anymore high refrigerant mass flows, but low ones as the consumption of the auxiliary 303 equipment are smaller. The optimization of the working point is essential, as the net 304 generation is drastically reduced if the working point is shifted.

305 Not to rely on the fan-coil, a second study is conducted assuming that the system is located 306 by a water reservoir. Figure 10 includes the thermoelectric and net generations if the 307 treatment of the water is not included, as the water is being continuosly taken from the 308 water reservoir (a lake, the sea or a river). The thermoelectric generation is from an 8 to 309 a $14 \%$ higher if just the cold plate is simulated. This increase is due to the reduction of 310 the thermal resistance of the system if the fan-coil is eliminated. Nevertheless, the biggest 311 change corresponds to the net generation which highly increases if the fan-coil is 312 eliminated from the refrigeration system. Increases of up to the $118 \%$ can be found, a 313 maximum net generation of $121 \mathrm{MWh} /$ year around occupancy ratios of 0.4 . Unlike the 314 previous study, practically all the net generations are positive, meaning that the 315 thermoelectric generation is higher than the consumption of the auxiliary equipment.

316 There is just a small region - highest water mass flow and smallest occupancy ratio- where 317 the net generation is negative due to the considerable consumption of the pump regarding 318 the thermoelectric generation. For low occupancy ratios, the thermal resistances were 319 barely dependent on the mass flow of the refrigerants. Thus high mass flows procure low 320 net generations. 


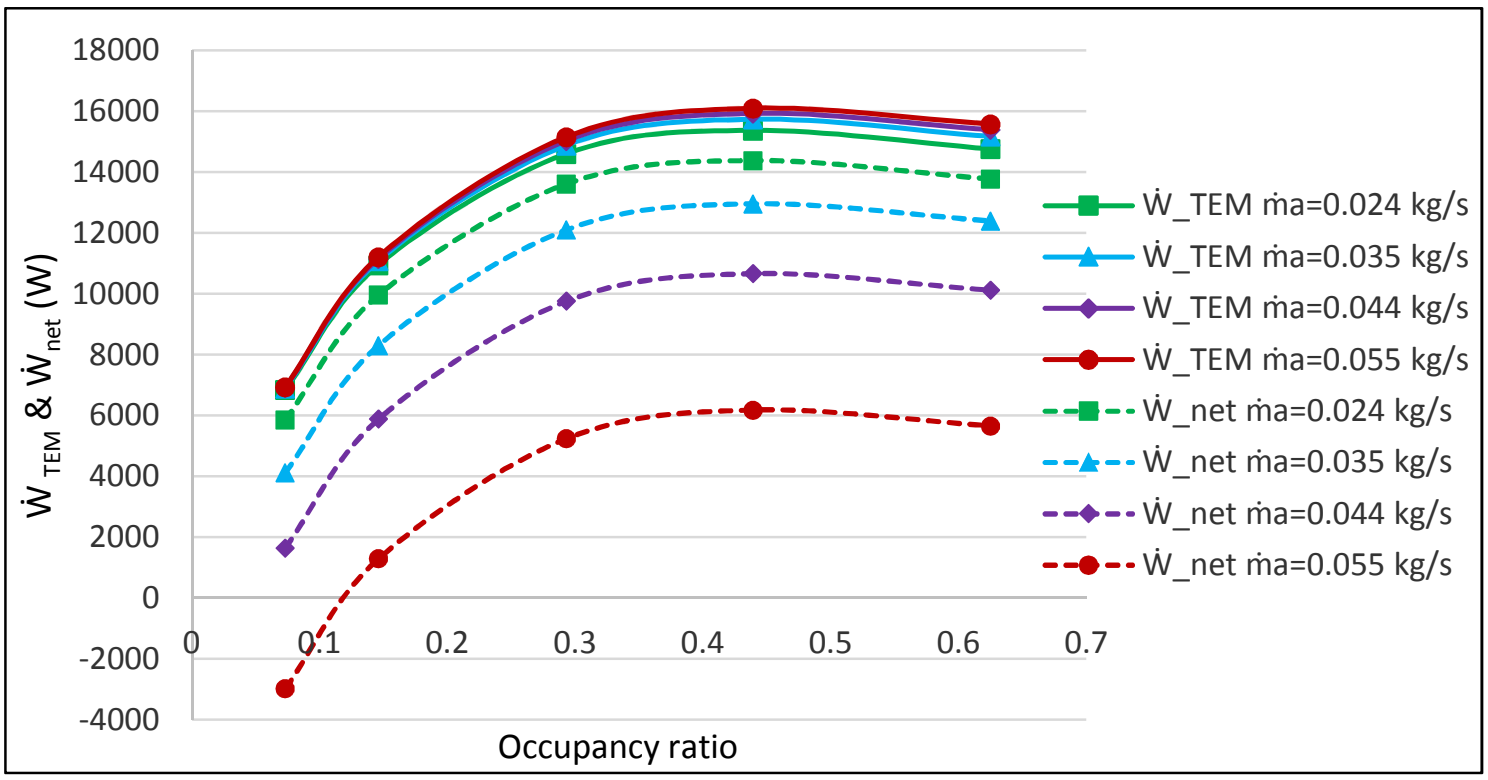

322 Figure 10. Net and thermoelectric generation of the cold plate as a function of the water mass flow and the occupancy ratio

324 The comparison between Figure 8, Figure 9 and Figure 10 present the great difference

325 between the results if the treatment of the refrigerant is included into the calculations or not. Excluding the fan-coil, is feasible but the application must be nearby a water resource and sadly not many applications present this scenario. A cooling tower could be a good solution because it presents small electric consumption. Nevertheless, its installation requires a lot of space and a big investment, resulting in a non-attractive solution unless

330 the TEG is installed into a big application provided with much free space. Between the maximum net generation of the first study (where the fan-coil and the consumption of its

332 fans are taken into account) and the one from the second one (where no fan-coil is 333 included), there could be different solutions as the consumption of the auxiliary

334 equipment could be optimized. The consumption of the auxiliary equipment is a deterrent, 335 as it shows the dramatic decrease in the net generation, hence it has to be taken into 336 account.

\section{Comparison with a novel technology}


338 The thermal resistances of the heat exchangers which involve refrigerants are very low,

339 producing high thermoelectric generations, however, as auxiliary equipment is necessary

340 to make the system work, the net generation is not as appealing as we could have thought.

341 Hence, a new dissipation system is studied, a phase change thermosyphon which includes

342 a refrigerant that changes phase and naturally moves through the system thanks to gravity,

343 meaning that no pump is needed. The fluid absorbs heat at the evaporator section, it

344 evaporates and ascends to the condenser, once condensed it returns to the evaporator

345 driven by the gravity force. To eliminate any auxiliary equipment, the condenser presents

346 a significant area provided with extended surface as the heat transfer coefficients are low

347 due to free convection.

348 A thermosyphon has been built and experimented to thermally characterize it as a function

349 of the occupancy ratio and the calorific power to dissipate. Figure 11 presents its diagram,

350 the hot plates simulate the heat flux that the system has to evacuate to the ambient. The

351 evaporator absorbs the heat and the inside liquid evaporates. The vapor ascends to the

352 condenser, where thanks to the extended surface it condenses and returns to the

353 evaporator, closing the cycle. The condenser area is $6.92 \mathrm{~m}^{2}$ and it is formed by 6 pipes,

354 of $10 \mathrm{~mm}$, distributed in 7 levels and crossed by longitudinal fins. The working fluid is 355 R134a. 


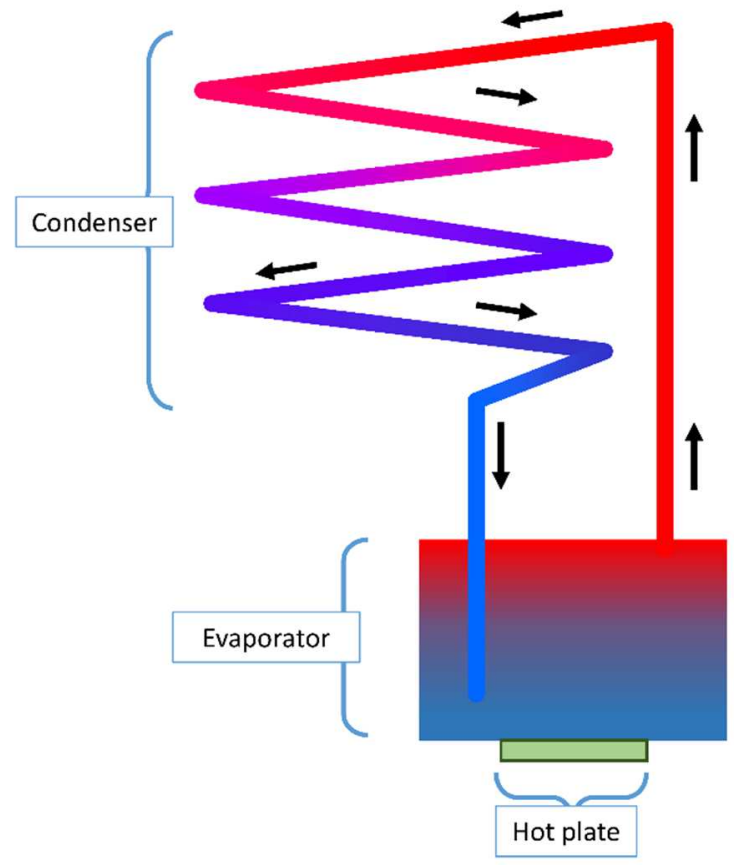

Figure 11. Thermosyphon diagram

358 Five values of occupancy ratios and six of calorific powers to dissipate have been selected to compute the thermal resistance. Three replicates have been made for each configuration

360 to reduce the uncertainty. The thermal resistance has been calculated using equation (5),

361 in this case $T_{C P}$ stands for the temperature of the thermosyphon, $T_{a m b}$ is the ambient

362 temperature and $\dot{Q}_{C}$ the calorific power to dissipate, this power is calculated multiplying

363 the voltage and intensity supplied to the hot plates, whose size is similar to that of the

364 TEMs. The overall uncertainty has been calculated using Coleman's work [26]. The

365 temperature probes used present an uncertainty of $\pm 0.5^{\circ} \mathrm{C}$ while the accuracy of the

366 voltmeters and ammeters are $\pm 0.2 \mathrm{~V}$ and $\pm 0.02 \mathrm{~A}$, respectively. The overall uncertainty

367 in percentage is smaller than the $8.5 \%$ in all cases. 


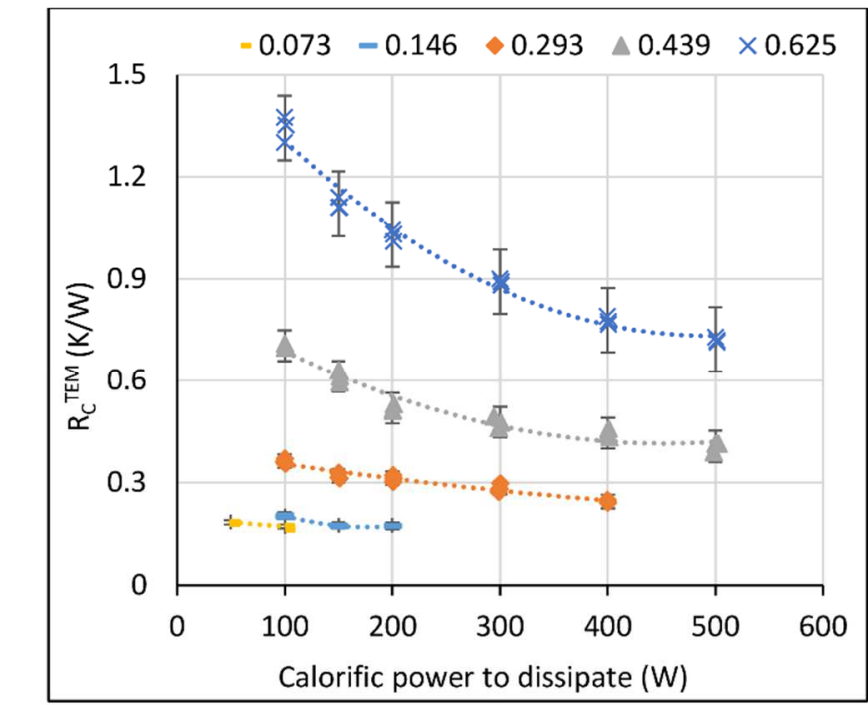

36 there is no auxiliary consumption.

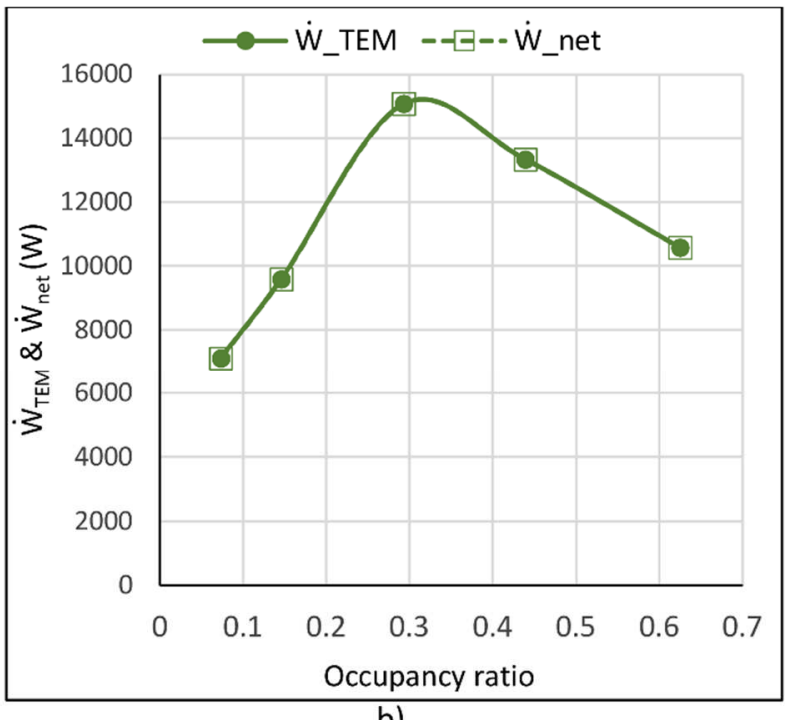

b)

Figure 12. Thermosyphon, a) thermal resistance per TEM as a function of the calorific power to dissipate and the occupancy ratio, a) net and thermoelectric generation

Figure 12a) includes the thermal resistances of the thermosyphon along with their uncertainty. In this case, the thermal resistance depends on both, the occupancy ratio and the calorific power to dissipate. The increase of the calorific power to dissipate increases the temperature of the working fluid and thus the heat transfer inside the thermosyphon improves. Moreover, the free convection that takes place outside the heat dissipation system improves as the temperature difference between the ambient and the outer wall increases. Due to the previous facts, the influence of the calorific power to dissipate is that influential on the thermal resistance of the system, as Figure 12 a) presents.

The thermoelectric generation and the net generation have been computed using the general methodology shown previously for the real case of the Spanish industry. For the thermosyphons, the net generation is similar to the thermoelectric generation because

Comparing Figure 7 and Figure 12 a) it can be seen that the thermal resistances of the thermosyphon for high occupancy ratios and low calorific powers to dissipate are higher than that for the refrigeration system. Nevertheless, as the calorific power to dissipate 
decreases, the thermal resistances considerably improve. The reduction of the thermal

387 resistances obtains higher thermoelectric generations than for the refrigeration system

388 with water, as Figure 12 b) shows. The optimal thermoelectric generation for the

389 thermosyphons, which occurs around an occupancy ratio of 0.3 , is $15200 \mathrm{~W}$. As the

390 thermosyphons do not need auxiliary equipment, the net generation corresponds with the

391 thermoelectric one. Thus an annual energy of 128 MWh can be produced from the waste

392 heat of a real Spanish Industry. This net generation is a $75 \%$ higher than that of the

393 refrigeration system with water and a $6 \%$ higher than the net generation obtained if there

394 is a water reservoir next to the dissipation system with a liquid as the heat-carrier.

395 The use of thermosyphons seems appealing. On the one hand, they operate by themselves,

396 without any auxiliary consumption or the necessity of a water reservoir next to them.

397 Nevertheless, on the other hand, they need a big surface area to assure that the fluid 398 condensates by free convection and they need to be located vertically, so gravity brings

399 back the condensates to the evaporator. Refrigeration systems with a liquid as the heat400 carrier need a smaller space to be located on the chimney, and if necessary, the heat 401 exchanger in charge of reducing the temperature of the refrigerant could be located 402 outside the installation. Thus, if the application presents restricted space, or the 403 refrigeration system cannot be found vertically, cold plates have to be used to refrigerate 404 the TEG, a very interesting solution that has to take into account the consumption of the 405 auxiliary equipment if the net generation wants to be optimized.

406

407

\section{Conclusions}

408 The computational methodology presents a net generation of $73 \mathrm{MWh} /$ year if a TEG 409 provided with a dissipation system with a fluid as the heat-carrier is installed in a real 410 application, a furnace located in Spain. However, the net generation could be up to 121 
$411 \mathrm{MWh} /$ year (a $66 \%$ higher) if the application was installed nearby a natural resource of

412 water.

413 All the applications where a TEG with dissipators including liquids as heat-carriers is

414 installed require a secondary heat exchanger to treat the refrigerant unless being nearby a

415 natural resource. The inclusion of a secondary heat exchanger, being in charge of reducing

416 the temperature of the refrigerant, influences on two parameters. Firstly, the thermal

417 resistance of the dissipation system is modified, as a reduction between the 8 and $14 \%$

418 in the thermoelectric generation shows. Secondly, the secondary heat exchanger normally

419 has auxiliary consumption that has to be taken into account. The studied case presents

420 reductions in the net generation of up to the $118 \%$, just because of including the auxiliary

421 consumption of the secondary heat exchanger. The thermoelectric generation is

422 important, but much more is the net generation. Any application where TEGs are installed

423 employ the net generation for other purposes, not the thermoelectric generation. Thus

424 each component included into a TEG, and its auxiliary consumption has to be borne in

425 mind when optimizing the application.

426 The installation of thermosyphons, which do not include any auxiliary equipment,

427 produces a higher net generation, $128 \mathrm{MWh}$ from the same application. Nevertheless, the

428 surface that these systems need is very big and they have to operate vertically so that

429 gravity can bring back the fluid to the evaporator.

430

431 Acknowledgments

432 The authors are indebted to the Spanish Ministry of Economy and Competitiveness for

433 the economic support to this work, included in the DPI2014-53158-R research project.

434 References

435 [1] Wang Y, Dai C, Wang S. Theoretical analysis of a thermoelectric generator using 436 exhaust gas of vehicles as heat source. Appl Energy 2013;112:1171-80. 
doi:10.1016/j.apenergy.2013.01.018.

[2] Wang X, Li B, Yan Y, Liu S, Li J. A study on heat transfer enhancement in the radial direction of gas flow for thermoelectric power generation. Appl Therm Eng 2016;102:176-83. doi:10.1016/j.applthermaleng.2016.03.063.

[3] Zhou M, He Y, Chen Y. A heat transfer numerical model for thermoelectric generator with cylindrical shell and straight fins under steady-state conditions. Appl Therm Eng 2014;68:80-91. doi:10.1109/IWECA.2014.6845673.

[4] Zheng XF, Liu CX, Yan YY, Wang Q. A review of thermoelectrics research Recent developments and potentials for sustainable and renewable energy applications. Renew Sustain Energy Rev 2014;32:486-503. doi:10.1016/j.rser.2013.12.053.

[5] Wang Y, Li S, Zhang Y, Yang X, Deng Y, Su C. The influence of inner topology of exhaust heat exchanger and thermoelectric module distribution on the performance of automotive thermoelectric generator. Energy Convers Manag 2016;126:266-77. doi:10.1016/j.enconman.2016.08.009.

[6] Lu C, Wang S, Chen C, Li Y. Effects of heat enhancement for exhaust heat exchanger on the performance of thermoelectric generator. Appl Therm Eng 2015;89:270-9. doi:10.1016/j.applthermaleng.2015.05.086.

[7] Amaral C, Brandão C, Sempels É V., Lesage FJ. Net thermoelectric generator power output using inner channel geometries with alternating flow impeding panels. Appl Therm Eng 2014;65:91-101. doi:10.1016/j.applthermaleng.2013.12.044.

[8] Ma T, Lu X, Pandit J, Ekkad S V., Huxtable ST, Deshpande S, et al. Numerical study on thermoelectric-hydraulic performance of a thermoelectric power generator with a plate-fin heat exchanger with longitudinal vortex generators. Appl Energy 2017;185:1343-54. doi:10.1016/j.apenergy.2016.01.078.

[9] Amaral C, Brandão C, Sempels É V., Lesage FJ. Thermoelectric power enhancement by way of flow impedance for fixed thermal input conditions. J Power Sources 2014;272:672-80. doi:10.1016/j.jpowsour.2014.09.003.

[10] Zhou S, Sammakia BG, White B, Borgesen P, Chen C. Multiscale modeling of Thermoelectric Generators for conversion performance enhancement. Int J Heat Mass Transf 2015;81:639-45. doi:10.1016/j.ijheatmasstransfer.2014.10.068.

[11] Aranguren P, Astrain D, Rodríguez A, Martínez A. Experimental investigation of the applicability of a thermoelectric generator to recover waste heat from a combustion chamber. Appl Energy 2015;152:121-30. doi:10.1016/j.apenergy.2015.04.077.

[12] Lu H, Wu T, Bai S, Xu K, Huang Y, Gao W, et al. Experiment on thermal uniformity and pressure drop of exhaust heat exchanger for automotive thermoelectric generator. Energy 2013;54:372-7. doi:10.1016/j.energy.2013.02.067.

[13] Aranguren P, Astrain D, Pérez MG. Computational and experimental study of a complete heat dissipation system using water as heat carrier placed on a thermoelectric generator. Energy 2014.

[14] Aranguren P, Astrain D, Martínez a. Study of Complete Thermoelectric Generator Behavior Including Water-to-Ambient Heat Dissipation on the Cold Side. J Electron Mater 2014;43:2320-30. doi:10.1007/s11664-014-3057-x.

[15] Shabgard H, Allen MJ, Sharifi N, Benn SP, Faghri A, Bergman TL. Heat pipe heat exchangers and heat sinks: Opportunities, challenges, applications, analysis, and state of the art. Int J Heat Mass Transf 2015;89:138-58. doi:10.1016/j.ijheatmasstransfer.2015.05.020. 
[16] Reay DA, Kew PA, McGlen RJ. Heat pipes: Theory, design and applications. 6th ed. Waltham, MA: Butterworth-Heinemann: Elsevier; 2014.

[17] Brito FP, Alves A, Pires JM, Martins LB, Martins J, Oliveira J, et al. Analysis of a Temperature-Controlled Exhaust Thermoelectric Generator During a Driving Cycle. J Electron Mater 2016;45:1846-70. doi:10.1007/s11664-015-4258-7.

[18] Remeli MF, Date A, Orr B, Ding LC, Singh B, Affandi NDN, et al. Experimental investigation of combined heat recovery and power generation using a heat pipe assisted thermoelectric generator system. Energy Convers Manag 2016;111:14757. doi:10.1016/j.enconman.2015.12.032.

[19] Singh R, Tundee S, Akbarzadeh A. Electric power generation from solar pond using combined thermosyphon and thermoelectric modules. Sol Energy 2011;85:371-8. doi:10.1016/j.solener.2010.11.012.

[20] Favarel C, Bédécarrats J-P, Kousksou T, Champier D. Experimental analysis with numerical comparison for different thermoelectric generators configurations. Energy Convers Manag 2015;107:114-22. doi:10.1016/j.enconman.2015.06.040.

[21] Angeline AA, Jayakumar J, Asirvatham LG, Marshal JJ, Wongwises S. Power generation enhancement with hybrid thermoelectric generator using biomass waste heat energy. Exp Therm Fluid Sci 2017;85:1-12. doi:10.1016/j.expthermflusci.2017.02.015.

[22] Weng C-C, Huang M-J. A simulation study of automotive waste heat recovery using a thermoelectric power generator. Int J Therm Sci 2013;71:302-9. doi:10.1016/j.ijthermalsci.2013.04.008.

[23] Aranguren P, Araiz M, Astrain D, Martínez A. Thermoelectric generators for waste heat harvesting: A computational and experimental approach. Energy Convers Manag 2017;148:680-91. doi:10.1016/j.enconman.2017.06.040.

[24] TG12-8-01L Power Generators | Generator Modules 2017. http://www.marlow.com/power-generators/standard-generators/tg12-8-011.html (accessed September 17, 2017).

[25] Mavridou S, Mavropoulos GC, Bouris D, Hountalas DT, Bergeles G. Comparative design study of a diesel exhaust gas heat exchanger for truck applications with conventional and state of the art heat transfer enhancements. Appl Therm Eng 2010;30:935-47. doi:10.1016/j.applthermaleng.2010.01.003.

[26] Coleman HW, Steele WG. Experimentation, Validation, and Uncertainty Analysis for Engineers. 3rd ed. New Jersey: John Wiley \& Sons; 2009. 